\title{
Task difficulty and conditioned suppression in humans
}

\author{
DAVID DESBIEN and DELPHINE YELEN \\ Washburn University, Topeka, Kansas 66621
}

\begin{abstract}
Conditioned emotional responses were produced by pairing a tone CS with 15 slides portraying surgical procedures. Presentation of the CS during color naming on a Stroop test resulted in significantly slower performance in a CER group than in a control group, but it had no effect on groups performing a word-reading Stroop task. It was concluded that some past failures to obtain conditioned suppression in humans might be due to the nature of the tasks used.
\end{abstract}

Studies using animal subjects have consistently shown that ongoing behavior can be disrupted by presentation of a conditioned stimulus that has previously been paired with a noxious unconditioned stimulus (Davis \& Wright, 1979). This disruption of behavior has been called conditioned suppression and has been attributed to the interfering effects of a conditioned emotional response (CER) established during the classical conditioning phase of training.

Attempts to demonstrate suppression with humans, however, have yielded mixed results. While some studies have shown conditioned suppression in humans (DiGiusto, DiGiusto, \& King, 1974; Reiter \& DeVellis, 1976), other investigators have found facilitation rather than suppression (Kanfer, 1958) or no effects of the CS (Sachs \& May, 1967). It seems possible that some of the inconsistency of the conditioned suppression results in humans may be a function of the type of tasks typically used in these studies. The type of task most often used in conditioned suppression studies with humans has involved a well-practiced response and/or a response that is very easy to perform. For example, verbal rate, leverpressing, buttonpressing, and solution of simple arithmetic problems have all been used. It is the argument of the present study that such tasks are generally insensitive to the interfering effects of the CER and that conditioned suppression can be readily demonstrated in humans when more difficult tasks are used.

The Stroop test, in which names of colors are printed in a color different from the one signified by the word can be used to produce two tasks: one very easy, namely reading the words, and a second, very difficult task, naming the colors of the words. The hypothesis tested in the present study was that conditioned suppression would occur in a group asked to perform the difficult color-naming Stroop task, but it would not occur in a group performing the easy word-reading Stroop task.

Requests for reprints should be sent to Delphine Yelen, Department of Psychology, Washburn University, Topeka, Kansas 66621.

\section{METHOD}

\section{Subjects}

A total of 52 volunteers from basic psychology classes who had been informed that they would be shown slides of surgical procedures participated in the experiment. Seven females and six males were randomly assigned to each of the four treatment groups formed by the factorial combination of type of task (color naming or word reading) and presence or absence of CER training.

\section{Materials}

All subjects were shown a series of 15 color slides taken from the film One in 20,000 (cited in Leventhal \& Watts, 1966). The slides depicted various stages of lung surgery; they began with a view of masked and gowned physicians and progressed through incision, several views of the lung, and closure of the incision. Subjects were given a 15-page booklet with a 7-point pleasant-unpleasant scale typed horizontally on each page.

During the second stage of the experiment, subjects were given a list of 40 words arranged in four columns. The words red, blue, yellow, black, and green printed in a color other than their own each appeared eight times on the list.

\section{Apparatus}

Subjects were seated $1 \mathrm{~m}$ from a $35 \times 40 \mathrm{~cm}$ white screen during the first stage of the experiment. Slides were projected onto the screen using a Kodak Ektagraphic slide projector equipped with a Lafayette 43016 shutter. The conditioned stimulus paired with the slides for the CER groups was a $2,000-\mathrm{Hz}$ tone generated by a Hewlett-Packard $200 \mathrm{CD}$ oscillator. Hunter timers were used to control the onset and offset of the tone and slides. Time to complete the color-naming or word-reading task was recorded on a Gerbrands G1280 clock that was manually started and stopped by the experimenter.

\section{Procedure}

During the first stage of the experiment, subjects were shown the 15 slides and asked to rate each for pleasantness. Each slide remained on for $6 \mathrm{sec}$, with a 5-sec interslide interval. After viewing each slide, subjects were instructed to place an " $\mathrm{X}$ " above any of the numbers 1 to 7 on a continuum ranging from pleasant to unpleasant. For half of the subjects, the $2,000-\mathrm{Hz}$ tone was presented $2 \mathrm{sec}$ before the onset of each slide and remained on until the slide went off $6 \mathrm{sec}$ later. The other half of the subjects, the control groups, were not exposed to the tone while viewing the slides.

In the second part of the experiment, half of the $26 \mathrm{CER}$ subjects and half of the 26 control subjects were assigned to the easy word-reading Stroop task and were asked to read the words 
as quickly and accurately as possible. The remaining 13 CER subjects and 13 control subjects were assigned to the difficult Stroop task and were asked to name the colors of the words as quickly and accurately as possible. All four groups were given five trials with their Stroop task. In all four groups, the CS was presented after the first five responses on each trial had been made; the CS remained on for $12 \mathrm{sec}$.

\section{RESULTS AND DISCUSSION}

Figure 1 presents mean time to complete the colornaming or word-reading task for the CER and control groups on each of the five Stroop trials. Inspection of the figure suggests that all groups showed some improvement over trials and that color naming was a more difficult task than was word reading. The data in Figure 1 also suggest little difference in level of performance between the word-reading CER group and the word-reading control group, but large differences existed between the two color-naming groups.

Analysis of variance of time to complete the task on Trials 1 and 5 for the four groups showed that, as predicted, the triple interaction of type of task, prior conditioning, and trials was significant $[F(1,48)=3.45$, $\mathrm{p}=.03$ ]. Accordingly, separate analyses of variance were performed on time to complete the task on Trials 1 and 5 for the color-naming groups and for the wordreading groups.

Analysis of the data for the word-reading groups showed that only the main effect of trials was significant $[F(1,24)=11.80, p<.01]$, with more rapid reading on Trial 5 than on Trial 1, as Figure 1 suggests. Presentation of the tone previously paired with the arousing slides during word reading did not interfere with ability to perform the task $[F(1,24)=2.16, p>.01]$, nor was there any difference in the degree of improvement in time to read the words between Trials 1 and 5 for the two groups $[F(1,24)=.06, p>.10]$. Thus, as predicted, conditioned suppression could not be demonstrated when the task was easy.

Analysis of variance of the data for the color-naming groups on Trials 1 and 5, however, indicated significant interference with performance in the CER group $[F(1,24)=7.84, p<.01]$. Thus, when the task used to measure the effects of CERs is difficult, conditioned suppression can be demonstrated.

The interaction of CER training and trials was also significant $[F(1,24)=7.84, p<.01]$. Inspection of the interaction suggests that the amount of interference with color naming produced by the tone in the CER group tended to decrease between Trials 1 and 5 . Since presentation of the tone during the color-naming task with-

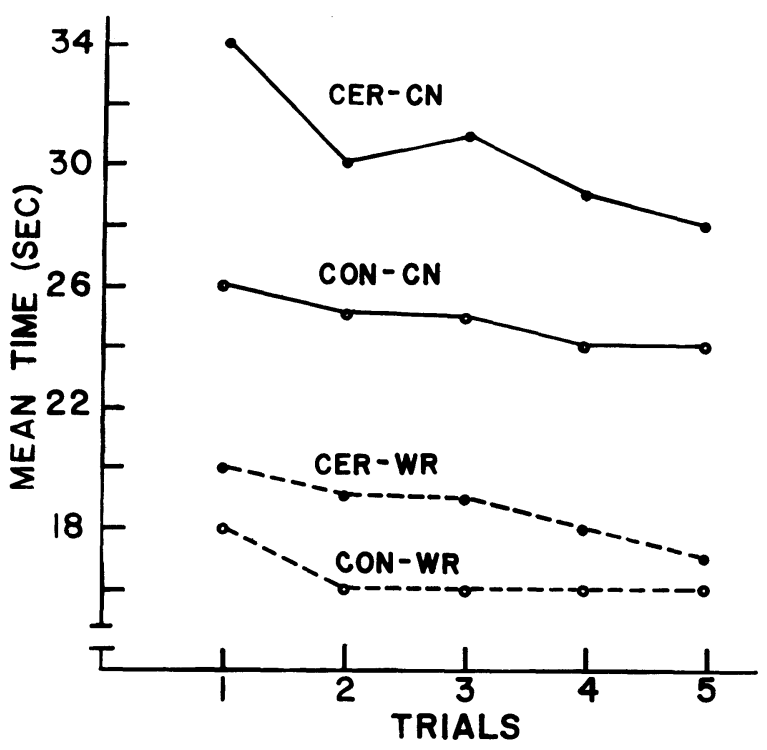

Figure 1. Mean time to complete color-naming $(\mathrm{CN})$ and word-reading (WR) tasks for the conditioned emotional response (CER) and control (CON) groups as a function of trials.

out the arousing slides constitutes a series of extinction trials for any CERs acquired, this interaction would be expected.

In summary, the results of the present study suggest that failure to find evidence for conditioned suppression in some past studies may have been due to the nature of the tasks used in those studies, rather than to inability to produce CERs.

\section{REFERENCES}

Davis, H., \& Wright, J. Procedural and parametric variability in studies of conditioned suppression. Bulletin of the Psychonomic Society, 1979, 14, 149-150.

DiGiusto, J. A., DiGiusto, E. L., \& King, M. G. Heart rate and muscle tension correlates of conditioned suppression in humans. Journal of Experimental Psychology, 1974, 103, 515-521.

KANFER, F. H. Effect of a warning signal preceding a noxious stimulus on verbal rate and heart rate. Journal of Experimental Psychology, 1958, 55, 73-80.

Leventhal, H., \& Watts, J. D. Sources of resistance to feararousing communications on smoking and lung cancer. Journal of Personality, 1966, 35, 155-175.

Reiter, L. A., \& DeVellis, B. M. Conditioned suppression in humans produced by a human stimulus. Journal of Personality and Social Psychology, 1976, 34, 223-227.

SAChS, D. A., \& MAY, J. G., JR. Conditional emotional response with humans: The effect of a variable interstimulus interval using a trace conditioning paradigm. Psychonomic Science, $1967,9,343-344$.

(Received for publication June 30, 1980.) 